\title{
Severe Hypothermia in the Sunshine State
}

\author{
Amninder Singh ${ }^{1}$, Tej G. Stead ${ }^{2}$, Rohan Mangal ${ }^{3}$, Paul Banerjee ${ }^{4}$, Latha Ganti ${ }^{5}$ \\ 1. Emergency Medicine, University of Central Florida / Healthcare Corporation of America Graduate Medical Education \\ Consortium, Orlando, USA 2. Emergency Medicine, Brown University, Providence, USA 3. Emergency Medicine, John \\ Hopkins University, Baltimore, USA 4. Emergency Medicine, University of Central Florida, Orlando, USA 5. Emergency \\ Medicine, Envision Physician Services, Orlando, USA
}

Corresponding author: Tej G. Stead, tej_stead@brown.edu

\section{Abstract}

The authors present a case of accidental hypothermia in a region with a warm climate. The article includes a review of the stages of hypothermia as well as the management of hypothermia. Clinicians need to be vigilant for this condition even in places with warm weather.

Categories: Emergency Medicine

Keywords: hypothermia, florida

\section{Introduction}

Primary accidental hypothermia is a drop in the core temperature to below $35^{\circ} \mathrm{C}$. There are four stages of hypothermia. Mild hypothermia (Stage I) clinically presents with temperature ranging between $32^{\circ} \mathrm{C}$ and $35^{\circ} \mathrm{C}$ in a conscious and shivering patient. Moderate hypothermia (Stage II) is defined as temperature ranging between $28^{\circ} \mathrm{C}$ and $32^{\circ} \mathrm{C}$. Patients with moderate hypothermia may have impaired consciousness. Severe hypothermia (Stage III) is distinguished by unconsciousness with the presence of vital signs and temperature from $24^{\circ} \mathrm{C}-28^{\circ} \mathrm{C}$. Stage IV is defined as hypothermia with absent vital signs [1].

\section{Case Presentation}

A woman in her 70s with a past medical history of chronic obstructive pulmonary disease (COPD), coronary artery disease, hypertension, bipolar disorder, schizophrenia, and alcohol abuse was brought in by ambulance after she was found down. She was found unresponsive outside of her home early in the morning, and the ambient temperature was $12.8^{\circ} \mathrm{C}\left(55^{\circ} \mathrm{F}\right)$. The patient was bradycardic, with a heart rate in the $40 \mathrm{~s}$, blood glucose of $64 \mathrm{mg} / \mathrm{dL}$, and blood pressure of 109/71 mmHg. She had a Glasgow Coma Scale (GCS) score of 3 with no gag reflex. The paramedics were unable to measure her temperature, as hers was too low to be read by their tympanic thermometer. The patient felt cool to touch. Upon arrival in the emergency department (ED), her heart rate was 36 beats per minute, blood pressure was $116 / 65 \mathrm{mmHg}$, and the patient was actively being ventilated by the paramedics with a bag valve mask. A temperature-sensing Foley catheter yielded a core temperature of $23.3^{\circ} \mathrm{C}\left(73.9^{\circ} \mathrm{F}\right)$. Her blood alcohol level was $90 \mathrm{mg} / \mathrm{dL}$.

Received 06/25/2019

Review began 06/26/2019 Review ended 07/05/2019 Published 07/06/2019

(c) Copyright 2019 Singh et al. This is an open access article distributed under the terms of the Creative Commons Attribution License CC-BY 3.0., which permits unrestricted use, distribution, and reproduction in any medium, provided the original author and source are credited.
The patient was immediately intubated for airway protection. She was actively warmed with warm intravenous (IV) fluids, convection warming blankets, and an invasive femoral temperature management catheter. The patient had a history of being on beta blockers per her medical record. Glucagon was administered in case of an underlying beta-blocker overdose. The patient continued to be hypotensive and bradycardic in the ED, despite fluid resuscitation. She was started on a low-dose dopamine and dobutamine drip and admitted to the intensive care unit (ICU).

About 12 hours into her ICU stay, the temperature increased to $32^{\circ} \mathrm{C}\left(89.6^{\circ} \mathrm{F}\right)$. She was awake, remained intubated, and followed commands. She was still acidotic with a $\mathrm{pH}$ of 7.1. The following day, she was extubated. She was discharged home a few days later, neurologically intact, with a diagnosis of severe hypothermia, metabolic acidosis, and alcohol abuse.

\section{Discussion}

The management of hypothermia initially begins with paying close attention to the airway, breathing, circulation, and re-warming. It can be difficult to assess for signs of life, especially in the later stages of hypothermia (Figure 1). Peripheral pulses are usually diminished due to vasoconstriction. It is important to check central pulses for signs of life, and for at least one minute prior to starting cardiopulmonary resuscitation, as hypothermic patients can be severely bradycardic. 


\section{Cureus}

\section{STAGES OF HYPOTHERMIA}

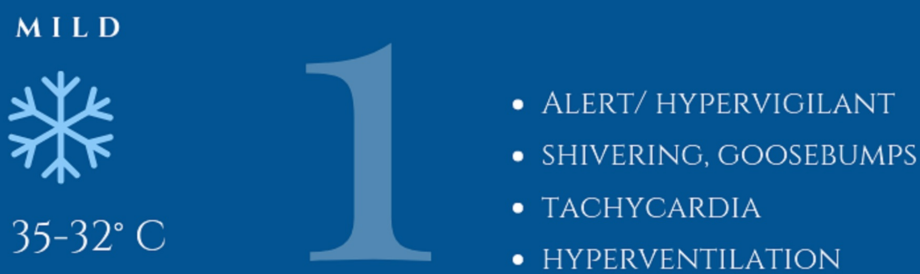

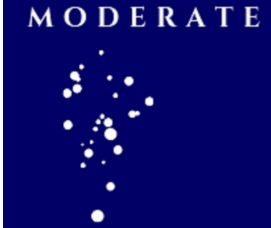

$32-28^{\circ} \mathrm{C}$

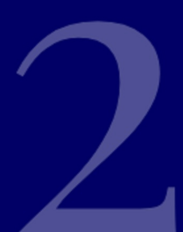

S E V E R E

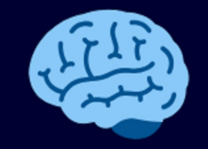

$28-24^{\circ} \mathrm{C}$

A B S E N T

V I T A L S

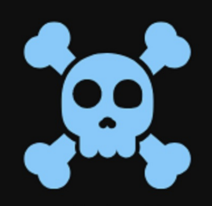

$<24^{\circ} \mathrm{C}$

- CONFUSION, APATHY, DIFFICULTY SPEAKING, INCOORDINATION

- INTENSE SHIVERING

- BRADYcaRdia

- BREATHING STARTS TO SLOW

\section{FIGURE 1: The four stages of hypothermia}

Graphic design by Karthik D. Stead

Rewarming should be started with passive and active core re-warming. Care must be taken not to warm the extremities initially, to prevent core temperature afterdrop, which occurs when the cold and acidotic blood present in the vasoconstricted extremity returns to the core circulation [2-3]. In our patient, we used an invasive femoral vein catheter to perform internal core re-warming. The femoral catheter circulated warm water until a target temperature of $34^{\circ} \mathrm{C}$ was achieved, with the goal of increasing the core temperature by $2{ }^{\circ} \mathrm{C}$ /hour. In hypothermic patients, the myocardium is very sensitive; hence, the placement of a central venous catheter in the internal jugular or subclavian vein is not preferred. The guidewire can irritate the myocardium and cause lethal dysrhythmias such as ventricular fibrillation or ventricular tachycardia. Also, care must be taken to avoid rough or unnecessary movement so as not to precipitate dysrhythmias [3]. The patient should also be transported horizontally as changes in position can affect venous return, which can 
Our patient remained hypotensive despite fluid resuscitation. We used dopamine and dobutamine as our first line of pressors. We did not want to use norepinephrine, as hypothermic patients are peripherally vasoconstricted. We did not want to risk limb ischemia with norepinephrine. There is limited literature on the choice of pressor in hypothermia. In swine studies with induced hypothermia, low-dose dopamine and dobutamine have been used to increase cardiac output, with no risk of inducing arrhythmias up to a max. dose of 30 micrograms $/ \mathrm{kg} / \mathrm{min}$ [4].

\section{Conclusions}

We describe a case of an elderly female with severe hypothermia of $23^{\circ} \mathrm{C}$. The patient had completely neurologically intact survival to discharge. In accidental hypothermia, care begins with avoiding aggressive movement, keeping the patient horizontal, passive, with active core rewarming and close attention to the patient's airway, breathing, and circulation. Vasoactive pressors, such as dopamine and dobutamine, can be used in the persistently hypotensive patient with severe hypothermia.

\section{Additional Information \\ Disclosures}

Human subjects: Consent was obtained by all participants in this study. Conflicts of interest: In compliance with the ICMJE uniform disclosure form, all authors declare the following: Payment/services info: All authors have declared that no financial support was received from any organization for the submitted work. Financial relationships: All authors have declared that they have no financial relationships at present or within the previous three years with any organizations that might have an interest in the submitted work. Other relationships: All authors have declared that there are no other relationships or activities that could appear to have influenced the submitted work.

\section{Acknowledgements}

This research was supported (in whole or in part) by HCA Healthcare and/or an HCA Healthcare-affiliated entity. The views expressed in this publication represent those of the author(s) and do not necessarily represent the official views of HCA Healthcare or any of its affiliated entities. Figure 1 was designed by Karthik D. Stead using Canva software (http://canva.com) under their free images licensing agreement. The authors provided the relevant medical content, which Mr. Stead organized into an infographic.

\section{References}

1. Brown DJA, Brugger H, Boyd J, Paal P: Accidental hypothermia. N Engl J Med. 2012, 367:1930-1938. 10.1056/NEJMra1114208

2. Paal P, Gordon L, Strapazzon G, et al.: Accidental hypothermia-an update. Scand J Trauma Resusc Emerg Med. 2016, 24:111. 10.1186/s13049-016-0303-7

3. Petrone P, Asensio JA, Marini CP: Management of accidental hypothermia and cold injury . Curr Probl Surg. 2014, 51:417-431. 10.1067/I.CPSURG.2014.07.004

4. Oung CM, English M, Chiu RC, Hinchey EJ: Effects of hypothermia on hemodynamic responses to dopamine and dobutamine. J Trauma. 1992, 33:671-678. 